\title{
Oral and Dermal Candidiasis Among Infants in Al-Battol Teaching Hospital
}

\author{
Raghad H Khaleefa $(\mathrm{BSc})^{1}$, Luma T Ahmed $(\mathrm{PhD})^{2}$ and Dawood S Hameed $(\mathrm{PhD})^{3}$
}

\section{Abstract}

Background: Candida spp. is the yeast caused infection termed candidiasis; this is naturally found on the skin and inner the body, in an area like the gut, intestines, throat, vagina, and mouth, with the absence inciting any problems. Candida albicans is yeast naturally found in the skin; intestinal tract; vaginal and mouth. This is a polymorphic yeast (that capable of growing either as avoid shaped budding yeast, when it affect the mouth, it is typically termed oral thrush, and when it affect the dermal (diaper area) called diaper rash. clinical signs and symptoms involve white patches on the or other areas of the mouth and throat, 'other signs may involve soreness and problems of swallowing.

Objective: To study detection, isolation, and identification of $C$. albicans from infants in Al-Battol Teaching Hospital in Diyala Province by routine laboratory procedure, and identification of other species of Candida.

Patients and Methods: Two hundred samples were taken from infants less than 2 years who attended Al-Battol teaching Hospital in Diyala, province during the period from October 2019 to February 2020. Method of this study by making a routine and confirmative diagnosis processes involve a microscopic examination, culture on Sabouraud's dextrose agar for diagnosis of primary invasive candidiasis, and culture on chrome agar for differentiating between $C$. albicans and other spp.

Results: The results of this study showed the isolates of oral samples were 12 (24\%) $C$. albicans and 18(36.0\%) C. non albicans; for dermal isolates were 10(20.0\%) C. albicans and $17(34.0 \%)$ C. non albicans; and for both isolates oral and dermal samples were 13(26.0\%) $C$. albicans and 21 (42.0) C. non albicans.

Conclusion: In this study found that the male are more infected by Candida than female. And also we concluded that small age children more infected than large age.

Keywords: C. albican, non-albicans Candida spp. , infants

Corresponding Author: raghad19931129@gmail.com

Received: $3^{\text {rd }}$ May 2020

Accepted: $23^{\text {th }}$ August 2020

DOI:https://doi.org/10.26505/DJM.19025350503

${ }^{1,2,3}$ Collage of Medicine - University of Diyala -Diyala- Iraq

\section{Introduction}

Candida is a type of fungus caused an infection called Candidiasis. Candida normally lives on the skin and inner of the

body. In areas like vagina, mouth, throat and gut without causing any proplems [1]. Among the at least 15 species of Candida 
yeasts that can infect humans. Candida albicans is the most prevalent [2, 3]. Candida albicans is the most common human fungal pathogen [4]. This also termed monilia; a fungus naturally found in the vagina mouth and intestinal tract. Under the circumstance, it's able to infect the surface of mucous membranes or skin. The C.albicans, C.parapsilosis, C.tropicalis, and C.glabrata these four species together account for $95 \%$ of identifiable candida infection [5].

It is usually termed oral thrush when it infected the oral cavity [6]. Symptoms and clinical signs include white patches on the tongue and other areas of the oral cavity and throat [7], other manifestation may involve problems swallowing and soreness [8], and it is naturally transferred vertically from mothers to infants through birth canal, and steal as a portion of normal human's microflora [9].

The highest prevalent human fungal infection is C.albicans, which described by an overgrowth of Candida species in the epithelium of the oral mucosa $[10,11]$. Candida species compose a portion of oral safe commensal flora in about $2-70 \%$ of the common populace [12].

Babies who are at highest risk for infection with candidiasis in the throat and mouth, and especially those less than one month of age and it's infrequent in the healthy adults $[13,14]$. Candidiasis in infants is reported to be $0.5-20 \%$, depending upon the different studies $[15,16]$.

The most prevalent type of candidiasis influence this age cluster is acute pseudomemberanous candidiasis [17]. White patches on an infant's tongue and/or oral mucosa are typically termed neonate thrush and named to as oral candidiasis [18, 19]. An infection induced by C.albicans tends to happen not many weeks after birth. Often presenting as napkin dermatitis or oral thrush, Candida infection is marked by very superficial blisters and plaques in intertriginous sites and pustules associated with the erythema. In the neonates it can also happen as systemic mycosis with disseminated candidiasis [20].

Diaper dermatitis is an irritant contact dermatitis occurring beneath the diaper of an infant related to factors like dampness, friction, urea, and feces. With technological improvement, the frequency of diaper dermatitis has decreased but the disease has not been eradicated[21]. Diaper dermatitis is seen mostly between 9 and 12 months. This condition is more common in children, but also can be seen in adults using diapers.

There is no difference between ethnic groups and gender [22]. The aim of this study detection, isolation and identification of C.albican from infants in Al-Battol Teaching Hospital in Diyala Province by using routine laboratory procedures, and identification of other species of Candida.

\section{Patients and Methods}

A study of 200 infants less than 2 years was carried out in Al- Battol Teaching Hospital, Diyala province for a period from October 2019 to February 2020. A detailed history of the infant, age, gender, body weight, and residency as urban, and rural . General physical and systemic examinations of all neonates were undertaken.An exhaustive dermatological examination was conducted to record physiological and 
pathological manifestations in neonatal skin and mouth. Special emphasis was laid on simple non-invasive laboratory investigations such as scraping for candida, pus swabs for bacterial culture, smear from pustules for grams stain, as indicated, and culturing of collected samples on Sabouraud's dextrose agar (SDA). To enhance the cultivation, the agar was used for primary isolation of Candida species selectivity; $(0.005 \mathrm{~g} / \mathrm{L})$ of chloramphenicol vial was added to the media. Oral and dermal samples that were collected by cotton swabs were streaked on the plates that contained the prepared media and incubated at $30^{\circ} \mathrm{C}$ for $48 \mathrm{hrs}$ for isolation of pure fungus (Candida) colonies. After the incubation period, the isolates were examined for their shape, color, size, and consistency. The plates were enclosed by parafilm to prevent contamination. Finally, they were stored in the refrigerator to keep for the culture [23]. Chromogenic Agar Candida (CAC) This method was prepared according to (Sheerihan, et al., 1999; Ibrahim et al., 2001). Chromogenic agar Candida is a medium used for the isolation and identification Candida spp. [24].

\section{Statistical analysis}

All data were statistically analyzed depending on SPSS (Statistical Package for Social Science) version 18 (2009).Chi-square and Yates's correction was used to compare the variables in this study. Statistical results were considered significant when being under or equal to $0.05[25]$.

\section{Results}

According to the gender in this study, the results showed that the percentage of males in the oral samples were $(56 \%)$ and $(44 \%)$ of females. Negative isolation accounted the highest percentage (40\%) followed by the $\mathrm{C}$. non albicans $(36 \%)$. Through Table (1), we note that the percentage of negative of males is the highest rate, as it reached (22\%), and for females, the highest rate was (18\%).

Demonstrated that the percentage of males in the dermal samples were $(64 \%)$ and the percentage of females (36\%), while the negative percentage was the highest at $(46 \%)$ followed by the C. non albicans (34\%). Through Table (1), we note that the percentage of negative of males is the highest rate, as it reached $(30 \%)$. while for females, the negative samples was the highest rate $(16 \%)$.

In addition the percentage of males in the mix samples were $(50 \%)$, and the percentage of females $(50 \%)$, while the C.non albicans percentage was the highest rate at (42\%) followed by the negative samples (32\%). Through Table (1), we note that the percentage of C.non albicans of males is the highest, as it reached (20\%). As for females, the C.non albicans samples were the highest by $(22 \%)$.

From the table, we conclude that there was no relationship between the results of the examination and gender in oral, dermal and mixed samples. 
Table (1): Candida infection rate among patients according to the gender

\begin{tabular}{|c|c|c|c|c|c|c|c|c|}
\hline \multirow{2}{*}{\multicolumn{4}{|c|}{ Group }} & \multicolumn{3}{|c|}{ Result } & \multirow{2}{*}{ Total } & \multirow[t]{2}{*}{ p-value } \\
\hline & & & & C. albicans & C. non albicans & Negative & & \\
\hline \multirow{6}{*}{ Oral } & \multirow{4}{*}{ Gender } & \multirow[b]{2}{*}{ Male } & Count & 5 & 12 & 11 & 28 & \multirow{6}{*}{0.399} \\
\hline & & & $\begin{array}{l}\% \text { of } \\
\text { Total }\end{array}$ & $10.0 \%$ & $24.0 \%$ & $22.0 \%$ & $56.0 \%$ & \\
\hline & & \multirow[b]{2}{*}{ Female } & Count & 7 & 6 & 9 & 22 & \\
\hline & & & $\begin{array}{l}\% \text { of } \\
\text { Total }\end{array}$ & $14.0 \%$ & $12.0 \%$ & $18.0 \%$ & $44.0 \%$ & \\
\hline & \multirow{2}{*}{\multicolumn{2}{|c|}{ Total }} & Count & 12 & 18 & 20 & 50 & \\
\hline & & & $\begin{array}{l}\% \text { of } \\
\text { Total }\end{array}$ & $24.0 \%$ & $36.0 \%$ & $40.0 \%$ & $100.0 \%$ & \\
\hline \multirow{6}{*}{ Derma } & \multirow{4}{*}{ Gender } & & Count & 6 & 11 & 15 & 32 & \multirow{6}{*}{0.957} \\
\hline & & Male & $\begin{array}{l}\% \text { of } \\
\text { Total }\end{array}$ & $12.0 \%$ & $22.0 \%$ & $30.0 \%$ & $64.0 \%$ & \\
\hline & & \multirow[b]{2}{*}{ Female } & 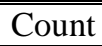 & 4 & 6 & 8 & 18 & \\
\hline & & & $\begin{array}{l}\% \text { of } \\
\text { Total }\end{array}$ & $8.0 \%$ & $12.0 \%$ & $16.0 \%$ & $36.0 \%$ & \\
\hline & \multirow{2}{*}{\multicolumn{2}{|c|}{ Total }} & Count & 10 & 17 & 23 & 50 & \\
\hline & & & $\begin{array}{l}\% \text { of } \\
\text { Total }\end{array}$ & $20.0 \%$ & $34.0 \%$ & $46.0 \%$ & $100.0 \%$ & \\
\hline \multirow{6}{*}{ Mix } & \multirow{4}{*}{ Gender } & & Count & 7 & 10 & 8 & 25 & \multirow{6}{*}{0.94} \\
\hline & & Male & $\begin{array}{l}\% \text { of } \\
\text { Total }\end{array}$ & $14.0 \%$ & $20.0 \%$ & $16.0 \%$ & $50.0 \%$ & \\
\hline & & & Count & 6 & 11 & 8 & 25 & \\
\hline & & Female & $\begin{array}{l}\% \text { of } \\
\text { Total }\end{array}$ & $12.0 \%$ & $22.0 \%$ & $16.0 \%$ & $50.0 \%$ & \\
\hline & \multirow{2}{*}{\multicolumn{2}{|c|}{ Total }} & Count & 13 & 21 & 16 & 50 & \\
\hline & & & $\begin{array}{l}\% \text { of } \\
\text { Total }\end{array}$ & $26.0 \%$ & $42.0 \%$ & $32.0 \%$ & $100.0 \%$ & \\
\hline
\end{tabular}

The analysis of data according to age showed that the minimum age for oral samples was 4 days and the maximum was 1080 days, and the Mean \pm SE was (229.98 27.15) and the SD was 191.98, and the minimum of body weight for oral samples was $2 \mathrm{~kg}$ and the maximum was $12 \mathrm{~kg}$, and the Mean \pm SE was $(6.7 \pm 0.328)$ and the SD was 2.32 .

In addition, results showed the minimum age for dermal samples is 5 days and maximum was 360 days, and the Mean \pm SE was $(175.32 \pm 16.99)$ and the SD was
120.15, and a minimum of body weight for oral sample was $1 \mathrm{~kg}$ and the maximum was $13 \mathrm{~kg}$, and the Mean \pm SE was $(6.56 \pm 0.37)$ and the SD is 2.643 .

The minimum age for mixed samples was 6 days and the maximum was 390 days, and the Mean \pm SE is $(1828.42 \pm 13.31)$ and the $\mathrm{SD}$ is 94.13 , and a minimum body weight for oral samples is $3 \mathrm{~kg}$ and the maximum is 10 $\mathrm{kg}$, and the Mean \pm SE is $(6.16 \pm 0.273)$ and the SD is 1.931 . 
Table (2): Candida infection rate among patients according to the age

\begin{tabular}{|c|c|c|c|c|c|}
\hline \multicolumn{6}{|c|}{ Descriptive Statistics for oral } \\
\hline & Count & Minimum & Maximum & Mean \pm S.E & $\begin{array}{c}\text { Std. Deviation } \\
\text { Statistic }\end{array}$ \\
\hline age per day & 50 & 4.00 & 1080.00 & $229.98 \pm 27.15$ & 191.98 \\
\hline Bodyweight(kg) & 50 & 2.00 & 12.00 & $6.7 \pm 0.328$ & 2.32 \\
\hline \multicolumn{6}{|c|}{ Descriptive Statistics for derma } \\
\hline Age per day & 50 & 5.00 & 360.00 & $175.32 \pm 16.99$ & 120.15 \\
\hline Bodyweight(kg) & 50 & 1.00 & 13.00 & $6.56 \pm 0.37$ & 2.643 \\
\hline \multicolumn{6}{|c|}{ Descriptive Statistics for mix } \\
\hline Age per day & 50 & 6.00 & 390.00 & $1828.42 \pm 13.31$ & 94.13 \\
\hline Bodyweight $(\mathrm{kg})$ & 50 & 3.00 & 10.00 & $6.16 \pm 0.273$ & 1.931 \\
\hline
\end{tabular}

According to the residency, the study of negative of urban is was (22\%), while for showed that the percentage of urban in the oral samples were $(50 \%)$ and the percentage of rural $(50 \%)$, while the negative percentage was $(40 \%)$ followed by C. non albicans (36\%). In Table (3), we note that the percentage of negative of urban is reached (20\%), while for rural areas accounted $20 \%$.

In addition, we observe that the percentage of urban in the dermal samples were $(36 \%)$ and the percentage of rural $(64 \%)$, while the negative percentage was the highest rate at (46\%) followed by the C.non albicans (34\%). rural, the C.non albicans accounted (30\%).

The percentage of urban in the mixed samples were $(54 \%)$ and the percentage of females (46\%), while the C.non albicans percentage was the highest rate at $(42 \%)$ followed by the negative (32\%). Through Table (3), we notice that the percentage of $\mathrm{C}$. non albicans of urban is $(26 \%)$, while for rural, the negative was (20\%). This indicates that there is no relationship between the results of isolation and residency in oral and mixed samples, and between the results of In Table (3), we observe that the percentage the isolation and residency in dermal Candida.

Table (3): Candida infection rate among patients according to the address

\begin{tabular}{|c|c|c|c|c|c|c|c|c|}
\hline \multirow{2}{*}{\multicolumn{4}{|c|}{ Group }} & \multicolumn{3}{|c|}{ Result } & \multirow[t]{2}{*}{ Total } & \multirow[t]{2}{*}{ p-value } \\
\hline & & & & \multirow{2}{*}{$\begin{array}{c}\text { C. albicans } \\
5 \\
\end{array}$} & \multirow{2}{*}{$\begin{array}{c}\text { C.non albicans } \\
10\end{array}$} & \multirow{2}{*}{$\frac{\text { negative }}{10}$} & & \\
\hline \multirow{6}{*}{ Oral } & \multirow{4}{*}{ Residencu } & & Count & & & & 25 & \multirow{6}{*}{0.757} \\
\hline & & Urban & $\begin{array}{l}\% \text { of } \\
\text { Total } \\
\end{array}$ & $10.0 \%$ & $20.0 \%$ & $20.0 \%$ & $50.0 \%$ & \\
\hline & & \multirow[b]{2}{*}{ Rural } & Count & 7 & 8 & 10 & 25 & \\
\hline & & & $\begin{array}{l}\% \text { of } \\
\text { Total }\end{array}$ & $14.0 \%$ & $16.0 \%$ & $20.0 \%$ & $50.0 \%$ & \\
\hline & \multirow{2}{*}{\multicolumn{2}{|c|}{ Total }} & Count & 12 & 18 & 20 & 50 & \\
\hline & & & $\begin{array}{l}\% \text { of } \\
\text { Total }\end{array}$ & $24.0 \%$ & $36.0 \%$ & $40.0 \%$ & $100.0 \%$ & \\
\hline \multirow{4}{*}{ Dermal } & \multirow{4}{*}{ Residency } & \multirow{2}{*}{ Urban } & Count & 5 & 2 & 11 & 18 & \multirow{4}{*}{0.037} \\
\hline & & & $\begin{array}{l}\% \text { of } \\
\text { Total }\end{array}$ & $10.0 \%$ & $4.0 \%$ & $22.0 \%$ & $36.0 \%$ & \\
\hline & & \multirow[b]{2}{*}{ Rural } & Count & 5 & 15 & 12 & 32 & \\
\hline & & & $\begin{array}{l}\% \text { of } \\
\text { Total }\end{array}$ & $10.0 \%$ & $30.0 \%$ & $24.0 \%$ & $64.0 \%$ & \\
\hline
\end{tabular}




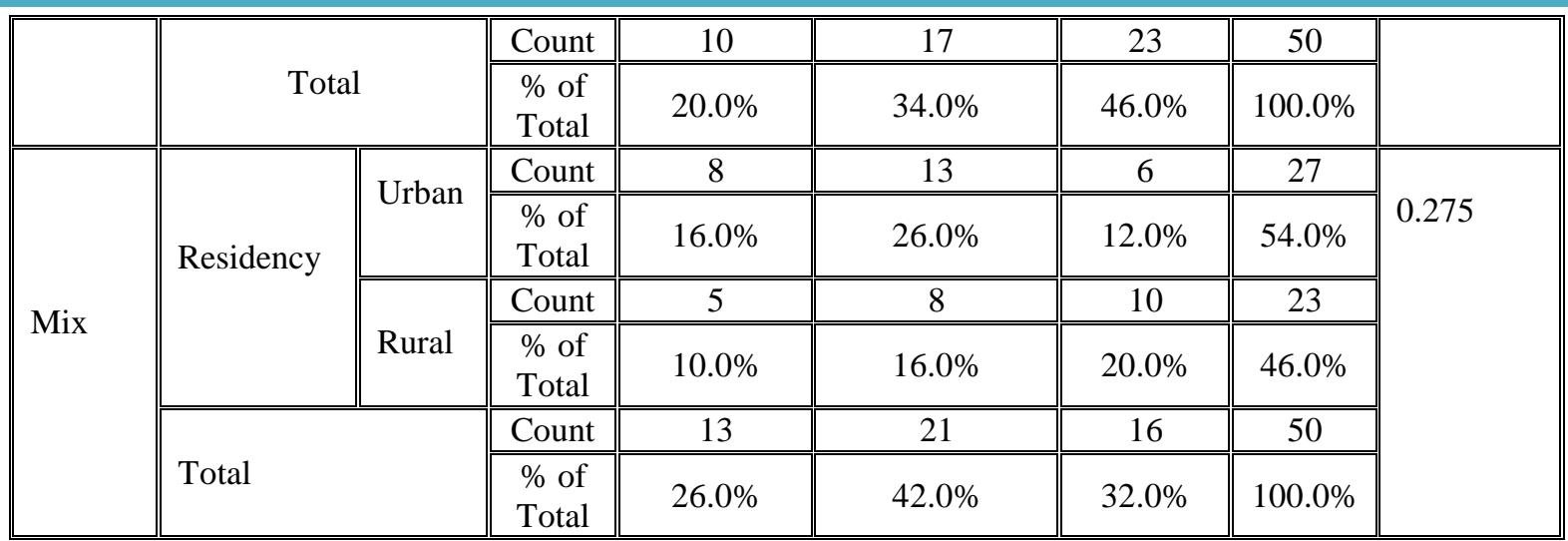

Through this study, it appeared that the percentage of soother used in the oral samples were $(60 \%)$ and the percentage of not soother used $(40 \%)$, while the negative percentage was $(40 \%)$ followed by the C.non albicans (36\%). Through Table (4), we notice that the percentage of negative of soother used was (26\%), while for non-soother users, the C.non albicans and negative was the highest percentage (14\%). The study also showed that the percentage of using soother in the dermal samples were $(66 \%)$ and the percentage of non-using soother was (34\%), while the negative percentage was the highest rate at $(46 \%)$ followed by the C.non albicans (34\%). Through Table (4), we notice that the percentage of C.non albicans and negative of using soother is (28\%), while non-using soother, the negative percentage was (18\%).

In addition, the results showed that the percentage of using soothe in the mixed samples was $(48 \%)$ and the percentage of non-using soother was (52\%), while the $C$. non albican percentage was the highest percentage at $(42 \%)$ followed by the negative (32\%). In Table (4), we notice that the percentage of $\mathrm{C}$. non albicans of using soother $(24 \%)$. As for non-using soother, the negative and $C$. non albicans was the highest percentage $(18 \%)$. This was due to the contamination of using the soother by children [32]. So this indicates that there was no relationship between the results of the examination and drug in the dermal, oral and mixed samples.

Table (4): Candida infection rate among patients according to the soother

\begin{tabular}{|c|c|c|c|c|c|c|c|c|}
\hline \multirow{2}{*}{\multicolumn{4}{|c|}{ Group }} & \multicolumn{3}{|c|}{ Result } & \multirow[b]{2}{*}{ Total } & \multirow[t]{2}{*}{ p-value } \\
\hline & & & & \multirow{2}{*}{$\begin{array}{c}\text { C. } \\
\text { albicans } \\
6\end{array}$} & \multirow{2}{*}{$\begin{array}{c}\begin{array}{c}\text { C.non } \\
\text { albicans }\end{array} \\
11\end{array}$} & \multirow{2}{*}{$\begin{array}{c}\text { Negative } \\
13 \\
\end{array}$} & & \\
\hline \multirow{6}{*}{ Oral } & \multirow{4}{*}{ Soother } & \multirow{2}{*}{ Used } & Count & & & & 30 & \multirow{6}{*}{0.699} \\
\hline & & & \% of Total & $12.0 \%$ & $22.0 \%$ & $26.0 \%$ & $60.0 \%$ & \\
\hline & & \multirow{2}{*}{ not used } & Count & 6 & 7 & 7 & 20 & \\
\hline & & & $\%$ of Total & $12.0 \%$ & $14.0 \%$ & $14.0 \%$ & $40.0 \%$ & \\
\hline & \multirow{2}{*}{\multicolumn{2}{|c|}{ Total }} & Count & 12 & 18 & 20 & 50 & \\
\hline & & & \% of Total & $24.0 \%$ & $36.0 \%$ & $40.0 \%$ & $100.0 \%$ & \\
\hline \multirow{4}{*}{ Derma } & \multirow{4}{*}{ Soother } & \multirow{2}{*}{ Used } & Count & 5 & 14 & 14 & 33 & \multirow{4}{*}{0.179} \\
\hline & & & $\%$ of Total & $10.0 \%$ & $28.0 \%$ & $28.0 \%$ & $66.0 \%$ & \\
\hline & & \multirow{2}{*}{ not used } & Count & 5 & 3 & 9 & 17 & \\
\hline & & & $\%$ of Total & $10.0 \%$ & $6.0 \%$ & $18.0 \%$ & $34.0 \%$ & \\
\hline
\end{tabular}




\begin{tabular}{|c|c|c|c|c|c|c|c|c|}
\hline & \multirow{2}{*}{\multicolumn{2}{|c|}{ Total }} & Count & 10 & 17 & 23 & 50 & \\
\hline & & & $\%$ of Total & $20.0 \%$ & $34.0 \%$ & $46.0 \%$ & $100.0 \%$ & \\
\hline \multirow{6}{*}{ Mix } & \multirow{4}{*}{ Soother } & \multirow{2}{*}{ Used } & Count & 5 & 12 & 7 & 24 & \multirow{6}{*}{0.524} \\
\hline & & & $\%$ of Total & $10.0 \%$ & $24.0 \%$ & $14.0 \%$ & $48.0 \%$ & \\
\hline & & \multirow{2}{*}{ not used } & Count & 8 & 9 & 9 & 26 & \\
\hline & & & $\%$ of Total & $16.0 \%$ & $18.0 \%$ & $18.0 \%$ & $52.0 \%$ & \\
\hline & \multirow{2}{*}{\multicolumn{2}{|c|}{ Total }} & Count & 13 & 21 & 16 & 50 & \\
\hline & & & \% of Total & $26.0 \%$ & $42.0 \%$ & $32.0 \%$ & $100.0 \%$ & \\
\hline
\end{tabular}

\section{Discussion}

Fungal infections still create the main health problem overall the world and affecting all ages particularly children. Therefore, many studies have been conducted concerning different epidemiological economic control as well as therapeutic features of this infection [40].

Candida organism is ubiquitous as it is commonly found on the skin and mucosal surfaces. It is estimated that $5-7 \%$ of babies less than one-month-old generally develop oral thrush. In general, the oral microbial flora and the body defenses keep this organism under control. But, when the body's defenses are compromised (such as HIV, cancer, chemotherapy/radiotherapy treatment, immunosuppression, or use of broad-spectrum antibiotics, etc.), then the colonization of this organism takes place [41]. In studies by Bassiri-Jahromi and Sberna, female patients were less affected by fungal infections than male patients [26,27]. On the other hand, several studies have indicated a higher incidence of superficial and cutaneous fungal infections in men compared to women $[28,29]$.The results also were similar to Sousa and coworkers [30] who found in their study that males $(32.0 \%)$ and females (67.7\%) and it was also nonsignificant in their study, and the result similar to Sanitá coworkers [31] who found that the number of females was more than males with non-significant differences among the groups . Also the results agreed with Premkumar coworkers [32] in their study that showed that females were higher infected (Male 47.5, Female 52.5).

But this study disagreed with Mohammadi coworkers (33) that have males higher than females $\quad(34 \quad(56.5 \%) \quad-23 \quad(40.4 \%)$ respectively. There was a non-significant relationship between Candida spp. isolation and gender. The explanation for such discrepancy may be due to the nature of the societies and duration of time for sample collection, hormonal factors and the highest incidence of iron insufficiency in women could be responsible for that disparity [34]. There was significant variation between males and females [34].

The results were in disagreement with Handa (2016), whom showed that $30.6 \%$ (83) of rural and $81.5 \%$ (440) of urban [35]. And Overall common of caries among infants was $54.6 \%$ in urban and $50.2 \%$ in rural areas [36].Urban areas generally have the highest cases of caries than rural areas due to most availability of refined diets. In comparison nearly half $(46.0 \%)$. of the children (8 days 16 years ) in the University of Port-Harcourt Teaching Hospital (UPTH) clinic had dental caries. This may be attributed to the more socioeconomic class of infants who patronize 
UPTH[37].The odds of having sexually transmitted infection was 1.85 times higher in women living in urban areas compared to the rural region [99\%C.I.1.29-2.65; $\mathrm{p}<0.001$ ], and 3.73 times most in women with vaginal discharge [99\%C.I. 2.60-5.35; p < 0.001] [38].

For weight infants with low weight suffers from candidiasis due to $10 \%$ of infants had candidemia for 14 days. Death or neurodevelopment injury was shown for 73 $\%$ of enormously low birth weight infants who lead to expanding candidiasis. Persistent candidiasis was mutual, delayed catheter extract was associated with rising NDI and death [39].

\section{Conclusions}

For the residency, children who lived in the urban are more infected than those living in rural areas. And finally, we concluded that children who used soothers are more infected than those not using soothers.

\section{Recommendations}

1.Genotyping of the isolated Candida spp.

2.We recommend that further confirmatory tests need to identify the genotypes origin by MLST technique or others modern technique.

\section{References}

[1]McCarty TP, Pappas PG. Invasive candidiasis. Infect Dis Clin North Am. 2016;30:103-24.

[2]Muzyka BC. Oral fungal infections. Dent Clin North Am. 2005;49:49-65.

[3]Beck-Sague, C.M. and W.R. Jarvis. 1993. National nosecomial infections surveillance system. Secular trends in the epidemiology of nosocomial fungal infections in the United states 1980-1990. J. Infect. Dis. 167, $1247-$ 1251 .
[4]Berman, J. Morphogenesis and cell cycle progression in Candida albicans. Curr Opin Microbiol (2006);9, 595-601.

[5]Public Health Agency of Canada. Candida albicans - Material Safety Data Sheets.

[6]Melkoumov A, Goupil M, Louhichi F, Raymond M, de Repentigny L, Leclair G. Nystatin nanosizing enhances in vitro and in vivo antifungal activity against Candida albicans. J .Antimicrob Chemother. 2013;68(9):2099-2105.

[7]Akpan A, Morgan R. Oral candidiasis. Postgrad Med J. 2002;78(922):455-459.

[8]L. P. Samaranayake, "Oral mycoses in HIV infection," Oral Surgery Oral Medicine and Oral Pathology, 1992; vol. 73, no. 2: 171-180.

[9]Epstein JB, Polsky B. Oropharyngeal candidiasis: a review of its clinical spectrum and current therapies. Clin Ther 1998;20:4057.

[10]Lalla RV, Latortue MC, Hong $\mathrm{CH}$, et al. A systematic review of oral fungal infections in patients receiving cancer therapy. Support Care Cancer 2010;18:985-92.

[11]Yilmaz A. E., Gorpelioglu C., Sarifakioglu E., Dogan D. G., Bilici M., Celik N. Prevalence of oral mucosal lesions from birth to two years. Niger. J. Clin. Pract.(2011); 14 349-353.

[12]Stecksen-Blicks C., Granstrom E., Silfverdal S. A., West C. E. Prevalence of oral Candida in the first year of life. (2015); Mycoses 58 550-556.

[13]Berdicevsky I., Ben-Aryeh H., Szargel R., Gutman D. Oral Candida in children. Oral Surg. Oral Med. Oral Pathol. (1984); 57 3740. 
[14]Baley J. E. Neonatal candidiasis: The current challenge. Clinics in Perinatology, (1991)18(2):, 263-280.

[15]Mathes E, Howard R. Vesicular, pustular, and bullous lesions in the newborn and infant. UpToDate. Available(2018).

[16]Dangi YS, Soni MS, Namdeo KP. Oral candidiasis: A review. Int J Pharm Pharm Sci. 2010;2:36-41.

[17]Ben Abdeljelil J, Saghrouni F, Khammari I, Gheith S, Fathallah A, Ben Said $\mathrm{M}$, et al. Investigation of a cluster of Candida albicans invasive candidiasis in a neonatal intensive care unit by pulsed-field gel electrophoresis. ScientificWorldJournal. 2012;2012:138989-138989.

[18]Ben Abdeljelil J, Saghrouni S, Nouri S, Geith I, Khammari A, Fathallah H, et al. Neonatal invasive candidiasis in Tunisian hospital: incidence, risk factors, distribution of species and antifungal susceptibility. Mycoses. 2012;55(6):493-500.

[19]Brecht M, Clerihew L, McGuire W. Prevention and treatment of invasive fungal infection in very low birthweight infants. Arch Dis Child Fetal Neonatal Ed. 2009;94(1):65-69.

[20]Benjamin DK, Jr, Stoll BJ, Gantz MG, Walsh MC, Sánchez PJ, Das A, etal .Eunice Kennedy Shriver National Institute of Child Health and Human Development Neonatal Research Network. Neonatal candidiasis: epidemiology, risk factors, and clinical judgment. Pediatrics. 2010;126(4):865-873. [21]Önder, M., Adışen, E. and Velagiç, Z, Diaper dermatit. Çocuk Sağlığı ve Hastalıkları Dergisi, 2007.,50(2), pp.129135.
[22]Birol A. Diaper dermatiti. In: Dermatoloji. Eds. Tüzün Y, Gürer MA, Serdaroğlu S, Oğuz O, Aksungur VL. 3 th Ed. İstanbul, Nobel Tip Kitabevi, 2008; 234 236.

[23]Deorukhkar SC, Saini S. Laboratory approach for diagnosis of candidiasis through ages. International Journal of Current Microbiology and Applied Sciences. 2014;3(1):206-18.

[24]Odds, F.C., and Bernaerts, R.I.A.. CHROMagar Candida, a new differential isolation medium for presumptive identification of clinically important Candida species. Journal of clinical microbiology, (1994) 32(8):19231929.

[25]Najwan, A.M.(2008). Detectiono f Candida spp.and other pathogens responsible for vulvovaginitis in women with contraceptive methods. M.Sc.Thesis, college of Science, Baghdad Univ.,Iraq. [26]Seebacher, C.; Bouchara, J. P., and Mignon, B.. Updates on the epidemiology of dermatophyte infections. Mycopathologia.(2008); 253533,(5-6);661.

[27]Samaranayake LP, Lamey PJ . Oral candidosis: Clinicopathological aspects. Dent Update. (1988); 15: 227-228, 230-1.

[28]Sardi, J. C.; Duque, C.; Höfling, J. F., and Gonçalves, R. B. Genetic and phenotypic evaluation of Candida albicans strains isolated from subgingival biofilm of diabetic patients with chronic periodontitis. Sabouraudia, (2012). 50(5): 467-475.

[29]Bassiri-Jahromi S. Epidemiological trends in zoophilic and geophilic fungi in Iran. Clin Expe Dermatol. 2013;38(1):13-9. [30]Ngwogu AC, Otokunefor TV. Epidemiology of dermatophytoses in a rural 
community in Eastern Nigeria and review of literature from Africa. Mycopathologia. 2007;164(4):149-58.

[31]Miklić P, Skerlev M, Budimčić D, Lipozenčić J. The frequency of superficial mycoses according to agents isolated during a ten-year period (1999- 2008) in Zagreb area, Croatia. Acta Dermatovenerol Croat. 2010;18(2):92-8.

[32]Edalatkhah H, Golforoshan F, Azimi H, Mohammadi P, Razi A. Prevalence of various species of dermatophytes in patients referring to the dermatology clinic of Tabriz Haft-e-Tir Hospital. J Ardabil Univ Med Sci. 2006;6(1):47-52.

[33]Sousa, M. G. D. M.; Costa, A. D. L. L. and Roncalli, A. G. Clinical study of the oral manifestations and related factors in type 2 diabetics patients. Brazilian journal of otorhinolaryngology. (2011) , 77(2): 145152.

[34]Sanitá, P. V. ; Pavarina, A. C.; Giampaolo, E. T.; Silva, M. M. ; de Oliveira Mima, E. G. ; Ribeiro, D. G.; and Vergani, C. E.. Candida spp. prevalence in well controlled type 2 diabetic patients with denture stomatitis. Oral Surgery, Oral Medicine, Oral Pathology, Oral Radiology, and Endodontology. (2011) , 111(6): 726733.

[35]Premkumar, J.; Ramani, P.; Chandrasekar, T.; Natesan, A.; and Premkumar, P. Detection of species diversity in oral candida colonization and anti-fungal susceptibility among non-oral habit adult diabetic patients. Journal of Natural Science, Biology, and Medicine. (2014) , 5(1): 148. [36]Mohammadi, F.; Javaheri, M. R. ; Nekoeian, S. ; and Dehghan, P. Identification of Candida species in the oral cavity of diabetic patients. Current medical mycology, (2016). 2(2): 1.

[37]Handa S, Prasad S, Rajashekharappa CB, Garg A, Ryana HK, Khurana C. Oral Health Status of Rural and Urban Population of Gurgaon Block, Gurgaon District Using WHO Assessment Form through Multistage Sampling Technique. J Clin Diagn Res. 2016;10(5):ZC43-ZC51.

[38]Ahmadnia E, Kharaghani R, Maleki A, et al. Prevalence and Associated Factors of Genital and Sexually Transmitted Infections in Married Women of Iran. Oman Med J. 2016;31(6):439-445.

[39]Daniel k. Benjamin ,Barbara j. stoll, Avory A. fanaroff, scott A. Mcdonald ,William oh ,rosmary D. Higgins, shahnaz Duara ,Kenneth poole ,Neonatal Candidiasis among extremely low birth weight infants :risk factors,mortality rates and neuorodevelopmental outcomes at 18 to22 months, Abbot laptook ,Ronald Goldberg and on behalf of the national institute of child health and human development neonatal research net work ,pediatrics January 2006,117(1)84:92.

[40]Seebacher, C.; Bouchara, J. P., and Mignon, B. (2008). Updates on the epidemiology of dermatophyte infections. Mycopathologia, 166(5-6), 335352.

[41]Samaranayake LP, Lamey PJ (1988) Oral candidosis: Clinicopathological aspects. Dent Update 15: 227-228, 230-1. 